\title{
Study on determination of errors in prescription writing: A semi- electronic perspective
}

\section{Ansari $\mathbf{M}^{1}$, Neupane $D^{2}$}

${ }^{1}$ Lecturer, Department of Pharmacology, Nobel Medical College \& Teaching Hospital, Biratnagar Nepal, ${ }^{2}$ Monitoring and Documentation Officer, Morang Innovative Neonatal Intervention, Nepal

\begin{abstract}
Background: Prescription writing is one of the most important and basic skills that a doctor needs. Prescribing errors may have various detrimental consequences. Hence, the components of a prescription should be clearly written, free of drug related omission (incomplete prescription), commission (incorrect information) and integration errors, without nonofficial abbreviations, and fulfil the legal requirements of a prescription. Since errors of prescribing are the commonest form of avoidable medication errors, it is the most important target for improvement.

Objectives: To estimate the types and prevalence of medication errors during transcription.

Materials and methods: A cross sectional descriptive retrospective study was conducted at Nobel Medical Teaching Hospital, Biratnagar, Nepal during a time period from $15^{\text {th }}$ November 2008 to $14^{\text {th }}$ February 2009 . A random sample of 268 prescriptions of patients written during a period of one year (18/06/2007 to 17/06/2008) for ten different medical out patient departments of the Hospital were reviewed and the analysis was carried out for determining the different types of errors in writing a prescription.

Results: No error was found regarding the name, age, sex and address of the patients. The error in prescriptions regarding the prescriber's name, qualification, NMC registration number and signature were 85.4\%, 99.6\%, 99.6\% and $15.7 \%$ respectively. Similarly, the symbol Rx was missing in $66.8 \%$. Dosage form, quantity, dose, frequency and route of administration were not mentioned in $12 \%, 60 \%, 19 \%, 10 \%$ and $63 \%$ of the prescriptions respectively. Likewise, strength of the prescribed medicines was not stated in $40 \%$ of the cases.

Conclusion: There is a need to critically address the legibility of prescription, correct spelling of drugs, authorised abbreviations and all other informations of a prescription concerned with patient, prescriber and drugs to minimise the occurrence of medication errors.
\end{abstract}

Key words: Drugs, Errors, Prescription, Rational, Writing

$\mathrm{P}$ escription is a written document that engages the medical and legal responsibility not only of the physician but of all those subsequently involved in its execution ${ }^{1}$. Prescription writing is one of the most important and basic skills that a doctor needs, thus specific training and supervision in prescription should be emphasised during undergraduate and postgraduate teaching to minimise related errors ${ }^{2}$.

Prescribing is a clinical skill that almost every physician practices regularly to transact the desired therapeutic goal $^{3}$. Correct prescription writing has a great influence on the fate of medicine therapy and health of patients. Errors in prescribing may be classified into two main types: errors of omission (incomplete prescription) and errors of commission (incorrect information) ${ }^{4}$. Prescribing errors may have various detrimental consequences. Hence, the components of a prescription should be clearly written, free of drug related omission (incomplete prescription), commission (incorrect information) and integration errors, without nonofficial abbreviations, and fulfil the legal requirements of a prescription ${ }^{3}$. Irrational prescription of drugs is a common occurrence in clinical practice ${ }^{5}$. Since errors of prescribing are the commonest form of avoidable medication errors, it is the most important target for improvement $t^{6,7}$. According to theories of human error, a series of planned actions may fail to achieve their desired outcome because the plan itself was inadequate or because the actions did not go as planned ${ }^{8}$. Medication prescribing deficiencies are the most common cause of actual and potential adverse drug events ${ }^{6,7,9}$.

Correspondence

Mukhtar Ansari

Lecturer, Department of Pharmacology

Nobel Medical College Teaching Hospital

Kanchanbari, Biratnagar (Morang), Nepal

E-mail: mukhtaransari@hotmail.com 
Difficulties can arise at any part of the prescription process from the moment the prescriber makes the choice of drug treatment to the time the patient receives that treatment $\mathrm{t}^{6,10}$. Incorrect prescribing, inadequate information given by the prescriber or the pharmacist and incorrect use of medicines by the patient can cause suffering to patients and expense to both patients and the community ${ }^{11,12,13,14,15,16,17}$. The magnitude of the problem may not be appreciated until a major adverse event happens. Therefore, it is important to monitor the performance of the system by paying attention to any problem that may arise ${ }^{18}$. The periodic evaluation of prescriptions can be a good tool to evaluate the rational use of drugs in terms of prescribing and dispensing and to evaluate patient understanding regarding drug usage $^{19}$.

\section{Materials and methods}

A cross sectional descriptive retrospective study was conducted at Nobel Medical Teaching Hospital, Biratnagar, Nepal during a time period from $15^{\text {th }}$ November 2008 to $14^{\text {th }}$ February 2009. A sample of 268 prescriptions from ten different medical Out Patient Departments (Medicine, Emergency, Surgery, Orthopedics, ENT, Dental, Pediatric, Obstetric \& gynecology, Ophthalmology and Psychiatry) written during a period of one year (18/06/2007 to $17 / 06 / 2008)$ by doctors of graduate level (eg. MD/MS) of the Hospital were chosen by using stratified random sampling method.

Data on patient's informations (patient's name, age, sex, address and OPD number), prescriber's informations (name of prescriber, NMC registration number, date and signature) and drugs' informations (name of drug, strength, dosage form, quantity, dose, frequency and the route of administration) were collected on a form designed by the authors using standard norms of prescription. The data collected by author's themselves, were entered in SPSS version 13.0 computer software and the analysis was made. The variables reviewed from the patient prescription records were patient name, patient age, patient sex, patient address, doctor's name, doctor's NMC registration number, doctor's signature and date of prescription, symbol Rx, drug's strength, dosage form, quantity, frequency and route of administration.

\section{Results}

Two hundred sixty eight prescriptions with a total of 795 drugs were reviewed and errors related to patient, prescriber and drug information were analysed.

No error was found in writing the name, age, sex and address of patients in the prescriptions. These variables were written in almost all prescriptions.

The study found that $15 \%$ of the prescribers had written their name on the prescription where as only $0.4 \%$ had written their qualification and NMC registration number on the prescriptions. The error in these two variables was found almost $100 \%$. However, more than $84 \%$ of the prescribers had signed the prescription. The error related to this variable was only 15.7 percent and about $67 \%$ error was found in writing the symbol Rx. About $9 \%$ of the prescriptions contained alternative symbols like Adv, T/T or DM for Rx.

According to Table 2, dosage form, quantity, dose, frequency and route of administration were not mentioned in $12 \%, 60 \%, 19 \%, 10 \%$ and $63 \%$ of the drugs respectively. Strength of the prescribed medications was not stated in $40 \%$ of the drugs and furthermore, strength was missing in about $2 \%$ of the drugs which were available in two or more strengths. Among the $60 \%$ of the drugs for which strength was mentioned, two percents were such drugs for which the stated strength did not exist. Two different brands each containing at least one same active component or two different drugs from the same class or category were prescribed in $2 \%$ of drugs. Unauthorised abbreviations like $\mathrm{T}$ or $\mathrm{Tb}$ for tablets, $\mathrm{C}$ or $\mathrm{C} / \mathrm{P}$ for capsules, $\mathrm{Adv}$ or $\mathrm{T} / \mathrm{T}$ or DM for Rx and O/D (looks like QID) for once daily dosing were detected in $14 \%, 1.5 \%, 9 \%, 2 \%$ of drugs respectively.

Table 1: Prescribing errors related to Transcriber's information ( $N=268)$

\begin{tabular}{|l|c|c|}
\hline Type of Error & Number of errors & Percentage of errors \\
\hline Name of prescriber & 229 & 85.4 \\
\hline Qualification & 267 & 99.6 \\
\hline NMC registration number & 267 & 99.6 \\
\hline Signature & 42 & 15.7 \\
\hline Rx & 179 & 66.8 \\
\hline
\end{tabular}


Table 2: Prescribing errors related to Drugs' information ( $N=795)$

\begin{tabular}{|c|c|c|}
\hline Type of Error & Number of errors & Percentage of errors \\
\hline Dosage form not mentioned & 96 & 12.1 \\
\hline Quantity/Duration not mentioned & 476 & 59.9 \\
\hline Dose not mentioned & 150 & 18.9 \\
\hline Frequency not mentioned & 83 & 10.4 \\
\hline Route not mentioned & 497 & 62.6 \\
\hline $\begin{array}{l}\text { Wrong spelling of drug (eg. Norfloxacillin for fluoroquinolone } \\
\text { norfloxacin) was found }\end{array}$ & 04 & 0.5 \\
\hline Unit of strength missing & 59 & 7.42 \\
\hline $\begin{array}{l}\text { Strength not mentioned } \\
\text { Not mentioned but available in two or more strengths } \\
\text { Strength not available but mentioned }\end{array}$ & $\begin{array}{c}322 \\
14 \\
16 \\
\end{array}$ & $\begin{array}{c}40.5 \\
1.76 \\
02\end{array}$ \\
\hline $\begin{array}{l}\text { Unauthorised abbreviations like } \\
\text { mgm for milligram } \\
\mathrm{Tb} \text { or } \mathrm{T} \text { for tablets } \\
\mathrm{C} \text { or } \mathrm{C} / \mathrm{P} \text { for capsules } \\
\mathrm{Adv} \text { or } \mathrm{T} / \mathrm{T} \text { or } \mathrm{DM} \text { for } \mathrm{Rx} \\
\mathrm{O} / \mathrm{D} \text { (looks like QID) for once daily dosing } \\
\mathrm{P} / \mathrm{O} \text { for oral } \\
\mathrm{PCM} \text { or PCT for Paracetamol }\end{array}$ & $\begin{array}{c}02 \\
109 \\
12 \\
72 \\
17 \\
03 \\
02\end{array}$ & $\begin{array}{c}0.25 \\
13.71 \\
1.5 \\
09 \\
2.14 \\
0.4 \\
0.25\end{array}$ \\
\hline $\begin{array}{l}\text { Two same drugs or of same category, eg. Tramadol \& } \\
\text { Pentazocin, Pacimol (Paracetamol 500mg) \& Flexon } \\
\text { (Ibuprofen 400mg + Pracetamol 500mg), } \\
\text { Diclofenac \& Flexon (Ibuprofen 400mg + Pracetamol 500mg) } \\
\text { prescribed in the same prescription. }\end{array}$ & 04 & 0.5 \\
\hline Nebulisation only, but the name of drug was mentioned. & 01 & 0.126 \\
\hline Hand writing unable to read & 05 & 0.63 \\
\hline
\end{tabular}

\section{Discussion}

The study has demonstrated a wide range of different types of error associated with prescription writing. This study showed that each prescription had at least one or more errors. The result is similar to the study carried out by V Mugoyela, S Mung'ong'o, S Mwita in Tanzania in $2008^{4}$. The $0 \%$ of error found in our study on writing variables like patient's name, age, sex and address is the result of use of computer software (MiDas). Regarding the error on writing name and signature of prescriber, higher percentage of error was reported in our study i.e $85.4 \%$ and $15.7 \%$ respectively as compared to the study conducted by Irshaid YM, Al Homrany M, Hamdi AA et $\mathrm{al}^{20}$ in Saudi Arabia in 2005 which is $16.7 \%$ and 18.1 percent respectively. It is common to prescribe medicines without writing NMC registration number in our setting (99.6\%). Similar pattern was found in a study conducted by Meyer TA ${ }^{21}$ in USA in 2000 (i.e. 89\%). Though the practice of writing registration number is less in our setting, it was found that the errors in writing dose $(18.9 \%)$, duration (59.9\%), dosage form (12.1 $\%)$, route $(62.6 \%)$ and illegible writing $(0.63 \%)$ are less as compared to other studies. The studies conducted by Irshaid YM, Al Homrany M, Hamdi AA. et al. in Saudi Arabia $^{20}$ and V Mugoyela, S Mung'ong'o, S Mwita in Tanzania ${ }^{4}$ found $44.4 \%$ and $5.4 \%$ error in writing dose respectively and $94 \%$ and $14.1 \%$ error in writing the duration of therapy respectively. This study has also found that about $83 \%$ drugs were prescribed by brand names and further more, some prescribed brands contained two same or similar drugs.

The findings clearly indicate that though there are some good practices on prescribing medicines, some measures seem intervention to address the issues of errors.

Further prospective studies regarding the harmful consequences associated with errors in prescribing is suggested.

\section{Conclusion}

It is found that each prescription had at least one or more errors. Therefore, there is a need to emphasise 
the legibility of prescription, correct spelling of drugs, authorised abbreviations and all other information of a prescription concerned with patient, prescriber and drugs to minimise occurrence of medication errors. An especial attention is required regarding the composition of combination drug preparations mainly when prescribed by brand names.

\section{Acknowledgements}

We extend our sincere thanks to Professor B R Prasai, Principal, Nobel Medical College for approving this study. We also would like to thank Chairman, Managing Director, Chief Executive Officer and faculty members for their valuable guidance to conduct this study. We especially thank Tikendra Shrestha, Pramod Raut and the Hospital staffs for their valuable support to this project.

\section{References}

1. Blatt A, Chambon R, Lemardeley P. Legal format and costs of prescriptions at the Central Hospital in Yaounde, Cameroon. Med Trop (Mars). 1997; 57(1):37-40.

2. Ferner RE. Medicines management: A sour taste. Q J Med. 2002; 95:181-4.

3. Shaughnessy AF, Nickel RO. Prescriptionwriting patterns and errors in a family medicine residency program. J Fam Pract. 1989; 29: 290-5.

4. Mugoyela V, Mung'ong'o S, Mwita S. Extent of Occurrence of Prescribing Errors in a Private Tertiary - Care Hospital in Dar es Salaam. Tanzania Medical Journal. 2008: 23(1).

5. Ramsay LE. Bridging the gap between clinical pharmacology and rational drug prescribing. $\mathrm{Br}$ J Clin Pharmacol. 1993; 35:575-6.

6. Leap LL, Bates DW, Cullen DJ, et al. Systems analysis of adverse events. JAMA. 1995; 274:35-43.

7. Bates DW, Cullen DJ, Laird N, et al. Incidence of adverse events and potential adverse drug events: Implications for prevention. JAMA. 1995; 274:29-34.

8. Reason J. Human error. Cambridge: University of Cambridge, 1990.

9. Kaushal R, Bates DW, Landringan C, et al. Medication errors and adverse drug events in pediatric inpatients. JAMA 2001; 285:2114-20.
10. Ferner RE. Errors in prescribing and giving drugs. J Med Defence union. 1992; 8:60-3

11. Manasse HR. Medication use in an imperfect world: Medicine misadventuring as an issue of public policy, part 1. Am J Hosp Pharm. 1989; 46:929-44.

12. Manasse HR. Medication use in an imperfect world: Medicine misadventuring as an issue of public policy, part 2. Am J Hosp Pharm. 1989; 46:1141-52.

13. Nathan A, Goodyer L, Lovejoy A, Rashid A. 'Brown bag medication reviews as a means of optimizing patients' use of medication and of identifying potential clinical problems. Family Practice. 1999; 16:278-82.

14. Westerlund T, Almarsdottir AB. Melander A. Drug-related problems and pharmacy interventions in community practice. Int $\mathrm{J}$ Pharm Prac. 1999; 7:40-50.

15. Bellingan M, Wiseman IC. Pharmacist intervention in an elderly care facility. Int $\mathrm{J}$ Pharm Prac. 1996; 4:25-9.

16. Greene R. Survey of prescription anomalies in community pharmacies: (1) prescription monitoring. Pharm J. 1995; 254: 476-81.

17. Stevens R, Balon D. Detection of hazardous drug/ drug interactions in a community pharmacy and subsequent intervention. Int $\mathrm{J}$ Pharm Pract. 1997; 5: 142-8.

18. S Nadeem H. Shah, Mohamed Aslam, Anthony J Avery. A survey of prescription errors in general practice. The Pharmaceutical Journal. 2001; 267:860-2.

19. Alam K, Mishra P, Prabhu M, et al. A study on rational drug prescribing and dispensing in outpatients in a tertiary care teaching hospital of Western Nepal. Kathmandu University Medical Journal. 2006: 16; 436-43.

20. Irshaid YM, Al Homrany M, Hamdi AA. et al. Compliance with good practice in prescription writing at outpatient clinics in Saudi Arabia. East Mediterr Health J. 2005; 11(5-6):922-8.

21. Meyer TA. Improving the quality of the order writing process for inpatient orders and outpatient prescriptions. Am J Health Syst Pharm. 2000; 57 Suppl 4:S18-22. 